\title{
Diagnosis of gonorrhoea in women
}

\author{
DAVID BARLOW, K. NAYYAR, I. PHILLIPS, AND J. BARROW \\ Department of Genito-urinary Medicine, St Thomas' Hospital, London
}

\section{Summary}

250 consecutive female contacts of men with gonorrhoea were examined in Lydia Department of Genito-urinary Medicine, St Thomas' Hospital, London, and 165 ( 66 per cent.) were found to be positive for gonorrhoea.

Over 99 per cent. of the positive results were found by the first two sets of genital investigations. These results are compared with earlier and more recent results from our own and other centres and it is postulated that the higher early diagnosis rate is due to the introduction of a highly selective but non-inhibitory culture medium (VCNT), combined with a new incubator which accurately regulates temperature, humidity, and $\mathrm{CO}_{2}$ content.

Reasons for the negative findings in 35 per cent. of the female gonorrhoea contacts are discussed.

\section{Introduction}

In a paper on vaginal discharge, Catterall (1970) reported that only 66 per cent. of patients eventually diagnosed as having gonorrhoea were found to be positive as a result of the first set of genital investigations. This figure rose to 86 per cent. after two sets of investigations. He emphasized the need for repeated examinations in those patients at risk.

In this clinic it has been the practice to investigate women on three separate occasions to diagnose or exclude gonorrhoea. Thin, Williams, and Nicol (1971), in a comparison of direct and delayed fluorescent techniques, diagnosed gonorrhoea in 90 per cent. by their first, 7 per cent. by their second, and 3 per cent. by their third set of genital tests. Since that time all gonorrhoea cultures have been examined by the delayed fluorescent staining method. In addition, certain improvements in culture media, incubation equipment, and techniques have prompted us to examine our current results with particular reference

Received for publication April 10, 1976

Address for reprints: Dr D Barlow: as above, London SE1 7EH to the percentage of cases diagnosed at successive visits.

Recently, Chipperfield and Catterall (1976) reappraised their gonorrhoea diagnostic results in women. They examined 207 consecutive female patients with gonorrhoea and found that more than 98 per cent. were diagnosed by two sets of investigations performed at an interval of 1 week. They recommend that three tests should still be performed on female contacts of men with gonorrhoea. Evans (1976) examined the results of 210 female patients who attended with gonorrhoea and found that 97 per cent. were diagnosed by the first two sets of investigations.

We have analysed the results of investigating 250 consecutive female patients who attended as contacts of men with gonorrhoea, and our findings are reported in this paper.

\section{Methods}

The patients were all seen in Lydia Department at St Thomas' Hospital. A history was taken, including details of dates of sexual intercourse, contraception, and any current or previous antibiotic treatment. Gram-stained smears of material from the urethra, cervix, and rectum were examined under the microscope and cotton-wool swabs from these sites were inoculated directly on culture plates with a selective medium containing vancomycin, colistin, nystatin, and trimethoprim (VCNT) Phillips, Humphrey, Middleton, and Nicol (1972). The plates were put into a candle-extinction jar in the clinic incubator and collected twice daily for transfer to the Department of Microbiology. There they were placed in an Assab incubator which automatically regulates temperature, humidity, and $\mathrm{CO}_{2}$ content. The plates were examined after 24 and $48 \mathrm{hrs}$ ' incubation and colonies were stained and examined by the fluorescent method described by Thin and others (1971).

If the initial investigations for Neisseria gonorrhoeae proved to be negative, they were repeated after approximately 2 days, as soon as the results were available from the laboratory, and if these again proved negative, the investigations were performed for a third time 1 week after the patient's first visit.

In addition to the tests for $N$. gonorrhoeae, vaginal slides and cultures were taken for the detection of Candida 
albicans and Trichomonas vaginalis. Blood was taken for treponemal serological tests.

\section{Results}

Of the 250 women investigated, 165 (65 per cent.), were found to be infected with $N$. gonorrhoeae. The majority of these were diagnosed by their first set of genital tests. Table I shows the percentage diagnosed at each visit and the method of diagnosiswhether by slide or culture or both. In $103(62.4$ per cent.) both slide and culture were positive, in 57 (34.5 per cent.) culture was positive but slides negative, and in five ( 3.1 per cent.) the slide was positive while the culture was negative. Overall, 108 (65.5 per cent.) would have been diagnosed if Gram-stained slide alone had been used.

TABLE I Method of diagnosis and percentage diagnosed at each visit

\begin{tabular}{|c|c|c|c|}
\hline Method & 1 st visit & 2nd visit & $3 r d$ visit \\
\hline $\begin{array}{l}\text { Slide + culture + } \\
\text { Slide - culture + } \\
\text { Slide + culture - }\end{array}$ & $\begin{array}{r}101 \\
55 \\
4\end{array}$ & $\begin{array}{l}1 \\
2 \\
1\end{array}$ & $\begin{array}{l}1 \\
0 \\
0\end{array}$ \\
\hline Total & $\begin{array}{c}160 \text { (97 per } \\
\text { cent.) }\end{array}$ & $\begin{array}{l}4(2.4 \text { per } \\
\text { cent.) }\end{array}$ & $\begin{array}{l}1 \text { (0.6 per } \\
\text { cent.) }\end{array}$ \\
\hline
\end{tabular}

Table II compares the percentages diagnosed at each visit in the present series with results from this hospital in 1971 (Thin and others, 1971) and with the results from the Middlesex hospital (Catterall, 1970 ; Chipperfield and Catterall, 1976). It is clear that a considerable improvement in results has occurred at both centres during the last few years.

TABLE II Comparison of number of tests needed in different series (per cent.)

\begin{tabular}{|c|c|c|c|c|}
\hline Series & 1 st visit & 2nd visit & 3rd visit & 4th visit \\
\hline Catterall (1970) & 66 & 20 & 10 & 4 \\
\hline Thin and others (1971) & 90 & 7 & 3 & - \\
\hline Chipperfield (1976) & 91 & $7 \cdot 1$ & 1.9 & - \\
\hline \multicolumn{5}{|l|}{ Barlow and others } \\
\hline (1976) & 97 & $2 \cdot 4$ & 0.6 & - \\
\hline
\end{tabular}

Associated infections in the 165 cases of gonorrhoea were: candidiasis 67 (41 per cent.), trichomoniasis 55 (33 per cent), and genital warts two (1 per cent.).

In 85 contacts the diagnosis of gonorrhoea was not established. Seven of these defaulted after only one set of investigations and five attended for only two tests. Of the 73 cases with three sets of negative tests, eleven were considered to be primary (source) contacts and 62 secondary contacts. Four primary and nine secondary contacts admitted taking antibiotics between exposure to risk and the time of examination. Three primary and three secondary contacts said that a condom had been used at the postulated time of infection. Three secondary contacts denied sexual intercourse during the 'at risk' period and in two secondary contacts there were grounds for doubting the original diagnosis of gonorrhoea in the partner.

\section{Discussion}

In Great Britain it is firmly believed by most genitourinary physicians that a diagnosis should be confirmed, rather than assumed, in gonorrhoea contacts. The diagnosis of gonorrhoea in the male is usually straightforward, the vast majority of cases giving positive results by a Gram-stained smear of urethral material. In the female, reliable microbiological support assumes much greater importance. Of our 165 positive cases, only 65 per cent. would have been diagnosed by Gram-stained smears alone. This figure is fairly constant in various clinics and compares with 60.8 per cent. from the Middlesex Hospital (Chipperfield and Catterall, 1976) and 57 per cent. from the West London Hospital (Evans, 1976). Because of this low percentage of positive results from smears alone, it has been customary to perform three or four sets of investigations on separate occasions to diagnose or exclude gonorrhoea in the woman.

In these days of financial stringency, it can be argued that, provided the microbiological service is of a high standard, only two sets of investigations need to be performed to diagnose or exclude gonorrhoea in women. If this approach were applied to secondary contacts it would be unlikely to lead to a significant number of untreated cases of gonorrhoea.

In this series $N$. gonorrhozae could not be found in 85 out of 250 female gonorrhoea contacts and in 78 of these (those having two tests or more) there are good reasons for believing that infection was not present. This proportion ( 35 per cent.) of negative results is higher than previously reported. As in the series of Chipperfield and Catterall (1976), who found 22 per cent. of gonorrhoea contacts to be uninfected, our patients included both primary and secondary contacts, some of whom were in a low-risk category. It is worth reflecting that all 85 patients would have been treated if we had a policy of 'epidemiological' treatment.

There are various factors to be considered as possible reasons for this high rate of negative findings among gonorrhoea contacts. There may have been no sexual contact when the partner was infectious ( 3 in our series), infection may have been prevented by barrier contraception such as the cap or condom (6 in our series), antibiotic treatment may have been administered for some other condition between the time of infection and the time of examination (13 in our series), and there may have been a faulty diagnosis in the partner (possibly 2 in our series). 
In addition to these quantifiable factors, there are others that are less easy to assess. Into this group come the problem of the infectivity of gonorrhoea, the part played by a zealous and efficient contacttracing team who may bring to the clinic a high proportion of low-risk contacts, and finally the question of laboratory failure.

The higher early diagnosis rate is probably due to the introduction of a highly selective but noninhibitory culture medium combined with better handling of samples and the use of a new incubator providing an improved environment for the growth of N. gonorrhoeae. Chipperfield and Catterall (1976) point out that their improved results were obtained using a culture medium that had no added antibiotics. Although their percentages diagnosed after two sets of investigations are similar to ours (Table
II), there is a difference in the results after one test (97 per cent.) as against 91 per cent.). We believe that this difference is due to the use of an antibiotic-containing medium (VCNT) which has been demonstrated to give a higher isolation rate for $N$. gonorrhozae when compared to a medium without added antibiotics (Phillips and others, 1972).

\section{References}

Catterall, R. D. (1970) Brit. F. vener. Dis., 46, 122

ChIPperfield, E. J., and Catterall, R. D. (1976) Ibid., 52, 36

Evans, B. A. (1976) Ibid., 52, 40

Phillips, I., Humphrey, D., Middleton, A., and Nicol, C. S. (1972) Ibid., 48, 287

Thin, R. N., Williams, I. A., and Nicol, C. S. (1971) Ibid., 47, 27 